\title{
Developing Hypertext-Based Learning Courseware for Computer Networks: The Macro and Micro Stages
}

\author{
Chien Chou, Member, IEEE
}

\begin{abstract}
In order to design and develop hypertext-based learning courseware for computer networks, we need to know human learning processes and how hypertext can be used to facilitate learning, to be aware of appropriate instructional theories and models to guide our design processes, and to consider pedagogical issues. The instructional systems development approach and the elaboration theory of instruction are introduced as the macro and micro stages of designing hypertext learning courses. The development of a sample course is reported. Discussions and a conclusion are provided.
\end{abstract}

Index Terms - Computer networks learning, courseware development, hypertext learning.

\section{INTRODUCTION}

$A$ LTHOUGH the concept of hypertext is not new [1], [2], the computer network-based hypertext is a relatively new research field. With the recent rapid advancement of computer networks and the popularity of on-line documents [3], the design and development of hypertext is becoming more and more necessary for engineering education.

Unlike traditional linear text, hypertext organizes information in sets of informational units connected by associative links. A hypertext system works like a database that stores materials and grants users maximal freedom to navigate through hyperspace. As Kolosseus et al. [4] suggested, the hypertext designer must learn new kinds of grammars that spatially organize information, to allow more flexible and dynamic control over it, and to provide more options for assimilating the information.

One of the major applications of hypertext to computer networks is delivery of learning and training courseware. Since engineering educational practitioners are often required to develop the courseware nowadays, hypertext design is becoming an increasingly important area of instruction in this field [5], [6]. In order to develop hypertext-based learning materials, we need to know human learning processes in general, and how hypertext can be used to facilitate learning. We also need to be aware of appropriate instructional theories

Manuscript received June 30, 1997; revised September 28, 1998. This work was supported by the National Science Council, Taiwan, ROC, under Contract NSC85-2511-S-009-006-CL.

The author is with the Institute of Communication Studies, National Chiao Tung University, Hsinchu, Taiwan.

Publisher Item Identifier S 0018-9359(99)01265-0. and have appropriate models to guide our design processes and to organize our information pedagogically.

\section{Designing Hypertext LEARNING COURSES}

Hypertext is considered by many researchers (e.g., [7]-[9]) to facilitate human learning. For example, in the most fundamental information-seeking stage of the human learning process, hypertext provides large integrated bodies of information in alternative representations for users to browse through selectively. Moreover, a hypertext document can contain any combination of text, graphics, sound, animation, and video. Using associative links and taking advantage of the structure of the information, users can find the information they need then progress to other learning activities.

After the initial information needs have been satisfied, the next stage is knowledge acquisition. In this stage, newly arriving knowledge is integrated with existing knowledge learners already possess through accretion, restructuring, and adaptation [7], [10]. Hypertext can facilitate this process by providing its interrelated ideas for users to access and assimilate, permitting dynamic control capabilities for users to integrate and reorganize information, and allowing collaborative authoring to adapt users' knowledge structures.

Some researchers such as Lee and Lehman [11], have emphasized the active role learners must play in order to learn in hypertext-based learning environments. Learners have to actively interact with the learning environment and contents by browsing, selecting, searching, scanning, tracing, and so on. Learning may occur when learners know not only what information is in a node, but also where and how to find that information within the web of nodes, and the structure or organization of that information. Some researchers such as Mayes et al. [12] even contend that some amount of disorientation and cognitive overhead are necessary in order to facilitate exploration and learning.

Given hypertext's potential for facilitating learning, and the popularity of computer networks, hypertext-based learning courses are becoming a major application of networks, and one of the principle skills engineering education practitioners must learn to adapt to. Among the most frequently asked questions these practitioners pose are:

-What instructional design stages or steps can I follow?

- What do I know about my target learner, and how do I know it? 
TABLE I

The Stages, Foci, and Tasks in the Development of a Hypertext Learning Course

\begin{tabular}{|c|l|l|l|}
\hline Stage & Question asked & \multicolumn{1}{|c|}{ Focus } & \multicolumn{1}{c|}{ Task } \\
\hline Macro & $\begin{array}{l}\text { Why } \\
\text { To whom }\end{array}$ & $\begin{array}{l}\text { Assessment of needs } \\
\text { Learner analysis } \\
\text { What }\end{array}$ & $\begin{array}{l}\text { Establish goals or enable objectives } \\
\text { Collect demographic data } \\
\text { Assess learner's prior knowledge and skills } \\
\text { Inventory learning tasks } \\
\text { Describe learning tasks }\end{array}$ \\
\hline Micro & How & Process & $\begin{array}{l}\text { Decide domain of information (information, } \\
\text { procedural, attitudinal) } \\
\text { Identify key concepts and sub-concepts } \\
\text { Sequence the learning tasks } \\
\text { Select design strategies } \\
\text { Preparc multimedia presentations }\end{array}$ \\
\hline
\end{tabular}

- How do I organize and present the learning materials?

The development of a hypertext learning course can be divided into two stages: macro and micro. Each stage has its focal points and tasks, as shown in Table I.

At the macro stage, decisions should be made regarding why, for whom, and for what the hypertext course is designed. The instructional systems development (ISD) approach can help us make these decisions. ISD is a systematic process for designing and producing instructional materials [13]-[15]. This approach usually includes the following steps.

1) Assessment of Needs: To determine what students need to be able to do after they have completed the hypertext course. The product of this step is a goal statement or a list of learning objectives.

2) Learner Analysis: To understand the target learners in demographic terms and a priori knowledge or skills possessed. Learner analysis helps designers set the entrylevel knowledge required for the course, and consider preentry training sessions to teach logging onto computer networks before the course is delivered to the target learners.

3) Task Analysis: To inventory, describe, and sequence the learning tasks and related knowledge or skills. Inventorying is the process of identifying the relevant tasks students need to learn to complete the course, while describing is the process of detailing the tasks identified in the inventory. In task analysis, one important factor is to identify the major learning domain in terms of information, motor skills, or attitudes. Determining the learning domain gives the course designer an initial idea of how to organize and sequence the instructional content [24]. Sequencing in more traditional computerassisted instruction (CAI) means specifying learning paths learners must follow in order to progress in the courseware. In hypertext courses, however, sequencing can mean the designers determining structure, in terms of placing and connecting nodes with links by the designer. We execute the process of sequencing in the micro design stages.

The ISD approach usually also involves selecting a delivery system. Since here we have already specified computer networks (e.g., the Internet) as the delivery system in the hypertext format, we skip this step and move directly to the micro design stage.

During micro design, detailed descriptions of the semantics that will be used to present information to learners are formulated. These include the sequencing, selection of examples, nonexamples, and specification of practices and application activities learners will use to acquire and consolidate their learning [16]. As Mengel and Adams [17] stated, methods are needed to help designers organize material into hypertext nodes. Among the many instructional theories and models available, some elaboration theory ideas are considered to be the most appropriate for development of hypertext learning courseware.

The elaboration theory [18]-[21] provides recommended techniques for analyzing instructional content in information domains, and proposes a top-down design process. This theory suggests a simple-to-complex approach to organizing instructions in which every level of instruction is detailed and epitomized. Instruction starts at a general level with an epitome that presents a very small number of the ideas to be taught in the course. Unlike general tables of contents or indices that present comprehensive abstract facts or terms that must be memorized, epitomes present one or at most a few of the most fundamental, generalizable, and inclusive concepts on concrete and meaningful levels. These general concepts are then elaborated upon in progressively more detailed steps. In addition to an epitome (overview), each level of elaboration may also have a summary (e.g., statement, example, or self-test), and/or a synthesis to help learners integrate the level of elaboration into all higher-level elaborations.

Reigeluth and Stein [18] used the "zoom lens" analogy to introduce their elaboration theory. Learners studying learning materials are in a way similar to photographers studying a picture through a camera zoom lens. They start with a wideangle view (at the zoom-out position) in which they have a chance to look at the major parts of the picture and to identify the major relationship among those parts. They then zoomin on a part of the picture to examine its subparts (details), and the interrelationships among those subparts. The learners can then zoom back out to the wide-angle view to review the 
other parts of the whole picture and to examine the contexts of certain parts within the whole picture.

The learners continue this pattern of zooming in to one level then in or out to other levels, or zooming in as far as the camera (detail) goes, or they can choose to follow their own interests in viewing the picture. The point here is that learners must start with wide-angle view, so they have an idea of the whole picture in mind. They will not start at or end up with any detailed subpart.

When used for developing hypertext courses, the elaboration theory suggests that contents be analyzed and the few most fundamental concepts be selected for presentation in the epitome node. Each concept has a link or links to its subordinate concept(s). In each subordinate-concept node, another epitome is provided that describes the lower-level subordinate concepts or facts. Information is thus fragmented in the nodes nested in the hypertext course.

The elaboration theory also suggests some design strategies, such as the use of analogies to help learners understand new ideas by relating them to familiar ideas. It encourages the use of pictures, diagrams, and other visual aids to force learners to interact with the content in certain specific ways. The theory also recommends granting learners control over content, pace, display format, and so on. These strategies are supported by the concept of hypertext, and are easily implemented in hypertext learning systems for computer networks.

The elaboration theory helps hypertext courseware designers make sure all important information is included in the learning content, and no unrelated information is included. It provides a much needed information structure for learners, and suggests some useful design strategies for courseware developers. It has been formatively evaluated to prove its effectiveness [21]. However, to evaluate whether it is feasible and has same effectiveness on computer networks, small units of a hypertext course were developed in my instructional message design course. The next section reports the process and the results of our courseware study.

\section{Case Study: A SAmple Hypertext-Based Course}

Instructional message design is a graduate-level course provided by the graduate Institute of Communication Studies at National Chiao Tung University (NCTU) in northern Taiwan. The course requires technical communicationmajor graduate students and in-service engineering educators to develop learning courses over interactive media such as computer networks. Learning courses for industrial training are in great demand by many Taiwan corporations. In fact, one of NCTU's neighbors is the National Sciencebased Industrial Park-Taiwan's Silicon Valley, where more than 165 high-tech companies such as Acer Computer are located.

In order to succeed in this course, students must have prior knowledge of computer networks and languages. Five graduate students recently qualified to take the course. Among them, two elective students were computer-science majors. In the course, they learned the hypertext concepts, design guidelines, and the instructional design theories and models mentioned above. Their collaborative final project for the course was to develop learning courseware units in the hypertext format to be delivered over a computer network, the Internet. The design guidelines they learned and tried to internalize in their designskills repertoire also served as checklists after completion of their final project.

The topic of their final project was computer networks. In other words, these graduate students had to develop a course to teach computer networks and deliver the course over a computer network. The major reason they selected this subject matter was because they were already familiar with it, so they could concentrate on the process in which the subject matter would be designed and developed into hypertext courseware.

Applying what they had learned about the macro design process, these graduate students followed the ISD approach in conducting needs assessments, learner analyses, and task analyses.

1) Assessment of Needs: Upon completion of the computer networks course, students should be able to understand the basic concepts, technology, and applications of computer networks.

2) Learner Analysis: The target learners for this course were freshmen noncomputer science majors, and any high school graduates interested in the topic of computer networks. Learners were required to have prior knowledge of and skills in using DOS, Windows, or MacOS. Since our course would be presented on the Internet, learners were required to know how to use Netscape in order to proceed with the course.

3) Task Analysis: The major learning domain for this course was identified as information, not motor skills (e.g., how to build up your own network system) or attitudes (e.g., appreciation of computer networks in daily life). The major learning tasks were inventoried, and included network applications, connections, communication hardware, communication software, data transmitting media, and network management and security. These learning tasks were further analyzed and described in detail; and information related to these tasks was collected. In this step, a content expert-a computer-science professor was invited to join the team.

The students made lists of major topics concerning all tasks on self-sticking sheets of paper (e.g., 3M post-it notes), and practiced building the structure of the content. After their time-consuming process of collaborative work, a hierarchical course structure was finalized on paper consuming more than 90 yellow stickers.

Among all the learning tasks in this network course, two were actually developed: transmission media and network topologies. The hierarchical structure of the units is shown 
below.

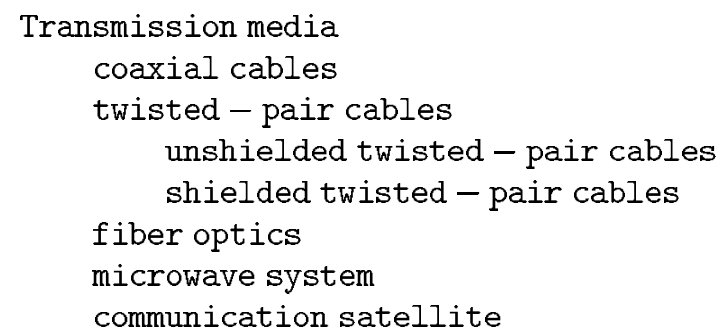

\author{
Network topologies \\ ring networks \\ token ring \\ bus networks \\ Ethernet net \\ star networks
}

At this stage, each topic or subtopic had only one or more terms. They looked like a lean table of contents or a structured index, and would not have provided a meaningful learning context in which learners could proceed with the course. Therefore, the next step was to move to the micro design stage to develop each topic into concrete and meaningful instructional nodes.

During the micro design stage, students started to write the content from scratch, rather than compiling materials already written by other authors. According to the elaboration theory, the few most fundamental concepts should be introduced first in the epitome, and then elaborated upon instructional nodes. Utilizing this theory, the transmission media epitome node had a statement, an analog, and a few most-fundamental key subtopics, as shown below (underlined words mean hot keys linked to related nodes):

Transmission media, also known as transmission channels, are physical media used to transport data from one computer to another. When designing a communication network to transmit data, we need to determine the type of transmission medium.

If we think of a communication network as our highway system, computers correspond to cities while the transmission medium corresponds to the roads between the cities.

Five types of transmission media are widely employed, they are twisted-pair cables, coaxial cables, fiber optics, microwave systems, and communication satellites.

The elaborated Fiber optic node was as follows:

Fiber optics are made of ultra-thin glass fibers of fused silica and are immune to electrical interference. Since each fiber supports only unidirectional transmission, each cable consists of two fibers in separate sheaths to provide bidirectional transmission.
Related topics:

- Fiber optics transmission rates

- Advantages and disadvantages of fiber optics

- The applications of fiber optics

The summary node for the five basic transmission media was presented in a tabular format:

\begin{tabular}{|c|c|c|c|c|c|}
\hline $\begin{array}{l}\text { Transmission } \\
\text { media }\end{array}$ & $\begin{array}{l}\text { Coaxial } \\
\text { cables }\end{array}$ & $\begin{array}{l}\text { Twisted-pair } \\
\text { cables }\end{array}$ & $\begin{array}{l}\text { Fiber } \\
\text { optics }\end{array}$ & $\begin{array}{l}\text { Micro- } \\
\text { wave }\end{array}$ & Satellite \\
\hline Signal form & $\begin{array}{l}\text { Electrical } \\
\text { pulses }\end{array}$ & $\begin{array}{l}\text { Electrical } \\
\text { pulses }\end{array}$ & $\begin{array}{l}\text { Light } \\
\text { pulses }\end{array}$ & $\begin{array}{l}\text { Radio } \\
\text { waves }\end{array}$ & $\begin{array}{l}\text { Radio } \\
\text { waves }\end{array}$ \\
\hline $\begin{array}{l}\text { Data rate per } \\
\text { second }\end{array}$ & $\begin{array}{l}60 \\
\text { megabits }\end{array}$ & 10 megabits & $\begin{array}{l}\text { Billions } \\
\text { of bits }\end{array}$ & - & - \\
\hline $\begin{array}{l}\text { Major } \\
\text { application }\end{array}$ & $\begin{array}{l}\text { Terminals } \\
\text { and com- } \\
\text { puters, } \\
\text { televi- } \\
\text { sion } \\
\text { transmis- } \\
\text { sions }\end{array}$ & $\begin{array}{l}\text { Token ring } \\
\text { in LANS }\end{array}$ & $\begin{array}{l}\text { Ethernet } \\
\text { in LANS }\end{array}$ & \begin{tabular}{|l} 
Short \\
point-to- \\
point \\
connec- \\
tions
\end{tabular} & $\begin{array}{l}\text { Multipoint } \\
\text { distribu- } \\
\text { tions, } \\
\text { teleconfer- } \\
\text { encing }\end{array}$ \\
\hline
\end{tabular}

A self-test node was also designed for learners to check their understanding of the learning content:

Question:

A small-scale business would like to build a LAN

of five computers within the same office to transmit data. Which transmission medium can best satisfy its needs and be most economical?

1) fiber optics;

2) coaxial cables;

3) twisted pair cables;

4) microwave system.

The final node designs were presented in a multimedia format, compiled in HTML, and delivered over the Internet. Fig. 1 shows the finalized fiber optics node as an example.

\section{Discussion AND CONCLUSIONS}

The sample courseware units in transmission media and network topologies, along with the rest of the units developed by myself and others, were formatively evaluated by 42 target learners, as reported by Sun and Chou [22]. In general, the evaluation indicated that learners did acquire basic knowledge from the course. Observations and interviews conducted during and after learning experiences indicated that learners felt arrangements and displays of learning materials were easy to understand and to follow. The simple-to-complex sequence helped learners build necessary learning contexts and confidence while proceeding on their learning journeys. The epitome also appeared to be quite effective in highlighting important relationships between subtopics, and between learners' related previous knowledge and what they were going to learn.

From the theories and case-study experience, we conclude that the following design guidelines that can be applied to the development of hypertext learning courseware at the macro level: 


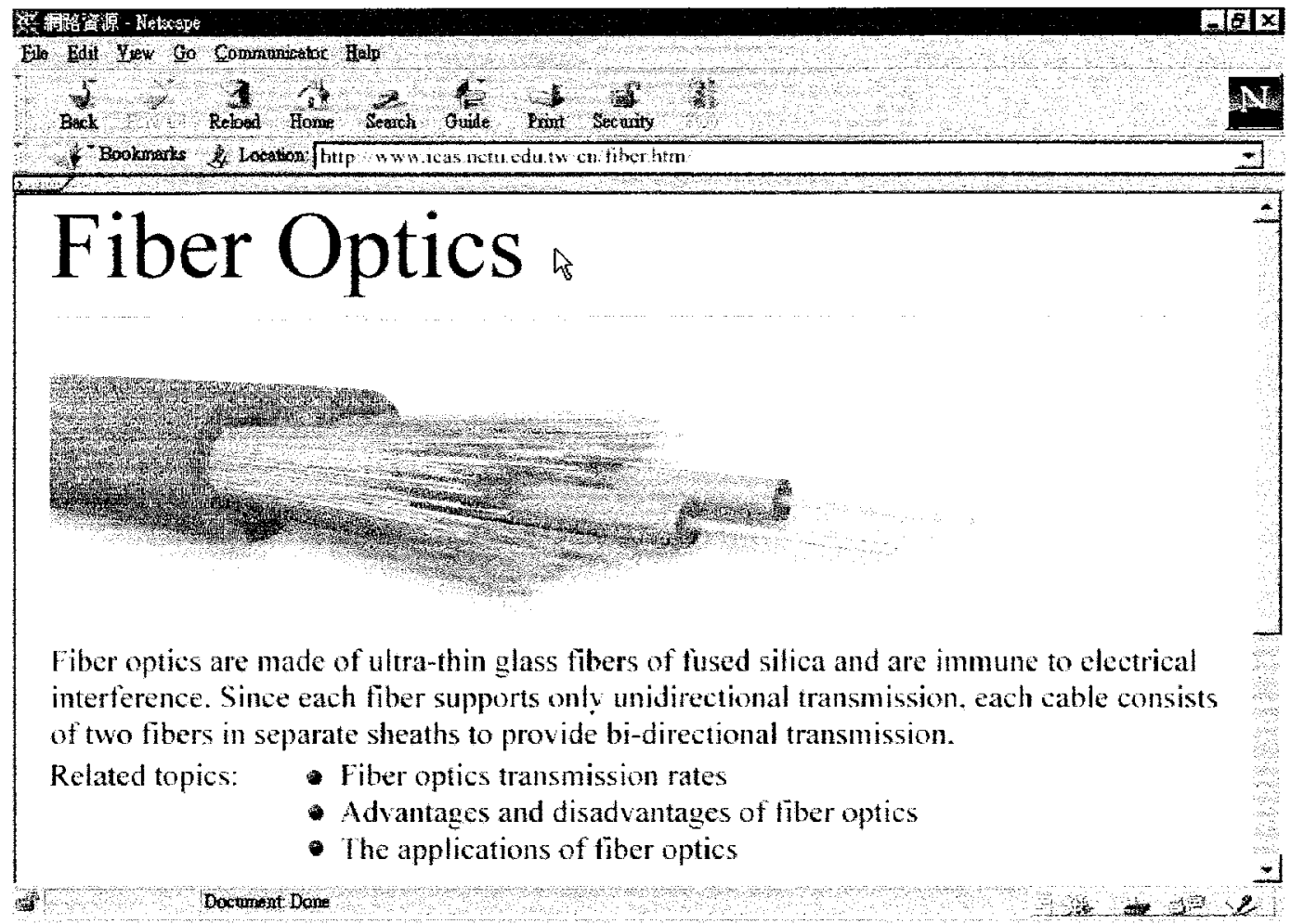

Fig. 1. The finalized fiber optics node in multimedia format.

1) Modularize learning information based on the elaboration theory.

2) Keep learning-node sizes to one screen-full of information with a maximum of two screens-full.

3) Provide elaborations on demand by designing elaborated and detailed information to be disclosed progressively as users demand it.

4) Construct meaningful interrelationships between learning nodes with embedded simple-to-complex sequences.

The construction of hypertext courseware for computer networks seemed an interesting and satisfying experience for both the graduate students taking this course and for me, the instructor. Students reported that they learned the guidelines and methodology involved in designing effective hypertext courseware. In the past, they had designed and developed homepages for their personal expression, cooperation promotion, or instructional purposes, based purely on their own intuition and impressions from others' homepages. The ISD approach helped them systematically focus on the goal, target learners, and learning tasks, while the elaboration theory helped them semantically organize the learning materials. Moreover, in order to teach the knowledge of computer networks, they got the chance to review and reconstruct the subject matter. This "learning by teaching" experience allowed them to have a deeper understanding of computer networks themselves.

\section{SUMMARY}

This paper discussed the much-needed concepts, skills, and example involved in developing hypertext learning courseware for computer networks. Given the increasing popularity of on-line documents and computer networks, this paper argues that engineering education professionals must learn the design methodology and acquire concrete hands-on development experience of hypertext learning courseware for networks. The ideas and example presented in this paper were some first steps toward addressing this requirement.

\section{REFERENCES}

[1] V. Bush, "As we may think," Atlantic Monthly, vol. 176, no. 1, pp. 101-108, 1945.

[2] J. Conklin, "Hypertext: An introduction and survey," IEEE Comput., vol. 20, no. 9, pp. 17-41, 1987.

[3] S. A. Selber, "Metaphorical perspectives on hypertext," IEEE Trans. Prof. Commun., vol. 38, pp. 59-67, 1995.

[4] B. Kolosseus, D. Bauer, and S. A. Bernhardt, "From writer to designer: Modeling composing processes in a hypertext environment," Techn. Commun. Quart., vol. 4, no. 1, pp. 79-93, 1995.

[5] R. A. Dumont, "Teaching and learning in cyberspace," IEEE Trans. Prof. Commun., vol. 39, pp. 192-204, 1996.

[6] P. Goubil-Gambrell, "Designing effective Internet assignments in introductory technical communication courses," IEEE Trans. Prof. Commun., vol. 39, pp. 224-231, 1996.

[7] D. H. Jonassen and R. S. Grabinger, "Problems and issues in designing hypertext/hypermedia for learning," in Designing Hypermedia for Learning, D. H. Jonassesen and H. Mandl, Eds. Berlin, Germany: Springer-Verlag, 1990, pp. 3-25.

[8] T. M. Duffy and R. A. Knuth, "Hypermedia and instruction: Where is the match?," in Designing Hypermedia for Learning, D. H. Jonassesen and H. Mandl, Eds. Berlin, Germany: Springer-Verlag, 1990, pp. 199-225.

[9] R. McAleese, "The acquisition and representations of domain specific knowledge using notecards," in Hypermedia Courseware Structures of Communication and Intelligent Help, A. Oliveira, Ed. Berlin, Germany: Springer-Verlag, 1991, pp. 11-18.

[10] D. H. Jonassen, "Semantic network elicitation: Tools for structuring hypertext," in Hypertext: State of the Art, R. McAleese, Ed. Oxford, U.K.: Intellect, 1990, pp. 142-152. 
[11] Y. B. Lee and J. D. Lehman, "Instructional cuing in hypermedia: A study with active and passive learners," J. Educational Multimedia and Hypermedia, vol. 2, no. 1, pp. 25-37, 1993.

[12] T. Mayes, M. Kibby, and T. Anderson, "Learning about learning from hypertext," in Designing Hypermedia for Learning, D. H. Jonassesen and H. Mandl, Eds. Berlin, Germany: Springer-Verlag, 1990, pp. 227-250.

[13] R. M. Gagne and L. J. Briggs, Principles of Instructional Design, 2nd ed. New York: Holt, Rinehart and Winston, 1979.

[14] W. Dick and L. M. Carey, The Systematic Design of Instruction, 4th ed. New York: Harper Collins, 1996.

[15] W. Dick, "The Dick and Carey model: Will it survive the decade?," Educ. Technol. Res. Development, vol. 44, no. 3, pp. 55-63, 1996.

[16] D. H. Jonassen and W. H. Hunnum, "Analysis of task analysis procedures," in Instructional Technology: Past, Present, and Future, G. J. Anglin, Ed. Englewood, CO: Libraries Unlimited, 1991, pp. 170-187.

[17] S. A. Mengel and W. J. Adams, "The need for a hypertext instructional design methodology," IEEE Trans. Educ., vol. 39, pp. 375-380, 1996.

[18] C. M. Reigeluth and F. S. Stein, "The elaboration theory of instruction," in Instructional Design Theories and Models: An Overview of their Current Status, C. M. Reigeluth, Ed. Hillsdale, NJ: Lawrence Erlbaum, 1983, pp. 335-382.
[19] C. M. Reigeluth, "Lesson blueprints based on the elaboration theory of instruction," in Instructional Theories in Action: Lessons Illustrating Selected Theories and Models, C. M. Reigeluth, Ed. Hillsdale, NJ: Lawrence Erlbaum, 1987, pp. 245-288.

[20] "Elaborating the elaboration theory," Educ. Technol. Res. Development, vol. 40, no. 3, pp. 80-86, 1992.

[21] R. E. English and C. M. Reigeluth, "Formative research on sequencing instruction with the elaboration theory," Educ. Technol. Res. Development, vol. 44, no. 1, pp. 23-42, 1996.

[22] C. T. Sun and C. Chou, "Experiencing CORAL: Design and implementation of distant cooperative learning," IEEE Trans. Educ., vol. 39,pp. 357-366, 1996

Chien Chou (M'94) received the Ph.D. degree in instructional design and technology from Ohio State University, Columbus.

She is an Associate Professor in the Institute of Communication Studies at National Chiao Tung University in Taiwan, where she teaches courses in multimedia message design, multimedia system evaluation, and multimedia video. 